\title{
1 Effects of Function-Based Models in Biologically 2 Inspired Design
}

\author{
Wei Liu ${ }^{a}$, Francesco Rosa ${ }^{b^{*}}$, Gaetano Cascini $^{b}$ and Runhua $\operatorname{Tan}^{a}$ \\ ${ }^{a}$ National Engineering Research Center for Technological Innovation Method and Tool, Hebei \\ University of Technology, Tianjin, China \\ ${ }^{b}$ School of Economics and Management, Hebei University of Technology, Tianjin, China \\ ${ }^{c}$ School of Mechanical Engineering, Hebei University of Technology, Tianjin, China \\ ${ }^{d}$ Dipartimento di Meccanica Politecnico di Milano, Milan, Italy
}

\begin{abstract}
Function-Based (FB) representations of complex systems play an important role in Biologically Inspired Design (BID) by easing the knowledge interchange among biologists, engineers and designers. Many representations have been proposed by scholars over the years, but none of them has ever become a clear favorite. As a matter of fact, each model represents the system from a distinctive perspective. This paper explores the effects of these different representations as creative stimuli for students in order to obtain recommendations for fostering innovation in education and training practices. After introducing a selection of FB models for BID, the paper describes an experiment designed to allow a quantitative comparison of the outcomes of a BID design challenge among undergraduate students attending a course on methods and tools for conceptual design. An analysis of the results of the experiment is followed by the authors' reflection on directions for educational development.
\end{abstract}

Keywords: Biologically Inspired Design; Knowledge representation; Ideation; Design creativity

\section{Introduction}

Biologically Inspired Design (BID) belongs to the family of what are called Design by Analogy methods (Helms et al., 2009; Fu et al., 2014; Kennedy, 2017). In particular, BID approaches rely on knowledge gained from Mother Nature to stimulate and supplement engineering design (Vandevenne et al., 2016). Notwithstanding the practical results and the in-depth scientific investigations in this field, there are still frequent debates on the reliability, efficacy and efficiency of BID in generating valid and creative alternative engineering solutions.

Among the several approaches that have been proposed, for example, Wanieck et al. (2016) identified 43 different "tools which facilitate the process of biomimetics." Our investigation focused on the methods relying on approaches based on Function-Based (FB) models of biological systems, since they constitute the great majority of the 43 "tools" identified by Wanieck et al. (2016). Furthermore, it is well known that the efficacy of systematic conceptual design methods is strongly affected by the design representation adopted, as confirmed by Cascini et al. (2018) among others. Therefore, in order to shed some light on these

\footnotetext{
*Corresponding author. Email: francesco.rosa@ polimi.it. Tel: (+39)02-2399-8275.
} 
aspects, the overall purpose of this project was to study how BID design representations affect the actual ability of young engineers to generate design solutions inspired by Mother Nature.

To explore the effects of these models on undergraduate students ${ }^{1}$ who attended courses on Methods and Tools for Innovation, we decided to perform a three-round experimental study. The first round was a free (i.e., without any supporting material) brainstorming session aimed at comparing the spontaneous ideation ability of the involved subjects. In the second and third rounds, the subjects were divided into six groups subjected to different treatments: BID models were provided to five groups, while one group (the control group) did not receive any additional information. The design task in the third round presented increased complexity, as it involved two functional requirements that required the students to connect multiple biological effects.

In turn, the lesson learned from the outcome of this experiment could be used to tailor the proper delivery of BID content in engineering education and industrial training, which is considered effective in enhancing multi-disciplinary collaboration and complex problem solving (Nagel et al., 2015) and, as such, in line with the research and education agenda embracing transdisciplinary thinking (Madni, 2007).

This paper is focused only on the first stage of the study, i.e., the comparison of different BID design representations in terms of efficacy in stimulating the ideation of design solutions.

The paper is therefore organized as follows: Section 2 briefly reviews the selected FB models. Section 3 explains the organization of the design experiment to compare the performance of the selected FB models in supporting BID ideation tasks. Section 4 introduces the metric used to analyze the experiment's results. Section 5 presents, analyzes and discusses the test outcomes. Finally, Section 6 concludes the whole paper by highlighting the main findings.

\section{Function-based biological knowledge representations}

The following tools have been selected for the experiment: Design by Analogy to Nature Engine (DANE); the State change, Action, Part, Phenomenon, Input, oRgan, Effect (SAPPhIRE) model; AskNature; Multi Biological Effects (MBE) and a model based on the UNified Ontology for Biologically Inspired Design (UNO-BID). AskNature was selected as it is the largest free online database of biologically inspired solutions and ideas; SAPPhIRE and DANE were chosen since they are the two FB models most widely discussed in the literature (Baldussu et al., 2012). UNOBID was the first model to integrate SAPPhIRE and DANE (Rosa et al., 2015), and MBE was the first attempt to represent Multiple Effects in a FB model (Wei et al., 2015), and thus are nominally more suitable for design tasks featuring several functional requirements. This section summarizes the selected FB-BID models and refers to their main elements.

\subsection{AskNature}

AskNature is a freely accessible on-line database created and maintained by the Biomimicry Institute (Shu et al., 2014). It contains more than two thousand biological ideation stimuli and is still under development (Deldin \& Schuknecht, 2014); as such, it has become one of the most popular knowledge sources for BID. Its capability of enhancing novelty in engineering design has been demonstrated in several case studies (Vandevenne et al., 2016).

The current AskNature database consists of four pieces of information: biological strategies, or biological prototypes used for inspiring innovations; inspired ideas, or exemplary practical implementations of biological strategies; collections, or sets of biological strategies to meet a certain functional requirement; and resources, or sets of relevant documents such as journal articles with detailed information on biological strategies.

\footnotetext{
${ }^{1}$ The subjects of this experiment were undergraduate students in mechanical engineering in the same class in their fourth year at Hebei University of Technology (China). These students had all passed the "Innovative Design" and "Modern Design Methodology" courses. There were no major differences between the groups in terms of age, gender, academic backgrounds or previous knowledge of BID. Further details are reported in section 3.
} 
Biological strategies are the core of the ideation stimuli and are sorted into different categories according to the biomimicry taxonomy, a three-layer taxonomy indicating functional characteristics (Vandevenne et al., 2016). A biological strategy involves several pieces of information:

- The biomimicry taxonomy indicates the functional characteristics of biological strategies.

- The biological strategy consists of pictures, short paragraphs and videos explaining how the biological prototype works.

- The reference mainly contains additional information in the form of links to relevant articles or books describing the biological phenomenon in depth.

\subsection{DANE}

DANE was conceived as an interactive knowledge-based method by adapting the Structure-BehaviorFunction (SBF) model to represent the functional characteristics of a biological system (Vattam et al., 2010). Structure, behavior and function, therefore, constitute the main body of the DANE model. The structure mainly represents substances and components of the system and the behavior describes the change of states in the biological system, while the function explains the purpose of the behavior.

Valuable features of DANE are (Rosa et al., 2015; Baldussu et al., 2012):

- The representation of the changes occurring on inputs produce the outputs through a certain process.

- A structure representation allows an explicit description of the structural relationships among these parts.

These features make it highly effective in revealing the internal features of a system and its "internal functioning" (Rosa et al., 2015).

\subsection{SAPPhIRE}

SAPPhIRE was first introduced as a behavioral language in IDE-INSPIRE software (Chakrabarti et al., 2005; Sarkar et al., 2008). Later, it evolved into an independent model able to represent causality in both natural and artificial systems (Srinivasan et al., 2013). After several years of developments (Srinivasan and Chakrabarti, 2007; Srinivasan \& Chakrabarti, 2010; Srinivasan et al., 2013), the SAPPhIRE model has evolved into a sophisticated technique for representing biological knowledge.

The main elements of SAPPhIRE are: State, which represents the attributes or properties in a given system that are involved in an interaction (Srinivasan \& Chakrabarti, 2007; Srinivasan et al., 2013); Action, which is an abstract description of system changes of state (Chakrabarti et al., 2005; Srinivasan et al., 2013); Parts, which are the physical components constituting the system (Chakrabarti et al., 2005); Physical phenomenon, which is a set of potential changes associated with a given physical phenomenon in an Organ (Srinivasan \& Chakrabarti, 2007); Effects, which are the laws enabling functions and/or interactions (Srinivasan \& Chakrabarti, 2007; Chakrabarti, 2009) and which are always described in forms of physical principles and/or mathematical equations; Input, which expresses the flows of energy, information or material that facilitate the change of state (Srinivasan \& Chakrabarti, 2007); and Organ, which works as a necessary carrier for the given physical effects and provides the material basis for biological function (Chakrabarti et al., 2005; Srinivasan \& Chakrabarti, 2007).

According to Baldussu et al. (2012), SAPPhIRE seems to be more suitable for describing complex systems as a whole and their interaction with the environment without describing in detail the internal "behavior" of the system, while highlighting the causality relationships among the system's main elements.

\subsection{UNO-BID}

UNO-BID ontology has been realized by integrating the DANE and SAPPhIRE models, relying on the complementarity of the information content of these two models (Rosa et al., 2015) with the final purpose of realizing a "universal" model for the BID practitioners. Although the UNO-BID modeling technique is still under development, preliminary investigations (Fayemi et al., 2017) have shown that: 
- UNO-BID seems to achieve the advantages of both the SAPPhIRE representation and DANE, with the downside of being difficult to handle and requiring time for implementation.

- UNO-BID seems to be more useful during the steps of the design process in which technical and natural systems are abstracted.

The models depicted in Figure 1 and in Appendix B represent, respectively, the archetype and an example of the model based on UNO-BID ontology that was adopted for this test. This model includes all the information that the underlying ontology can account for.

Legend of the symbols

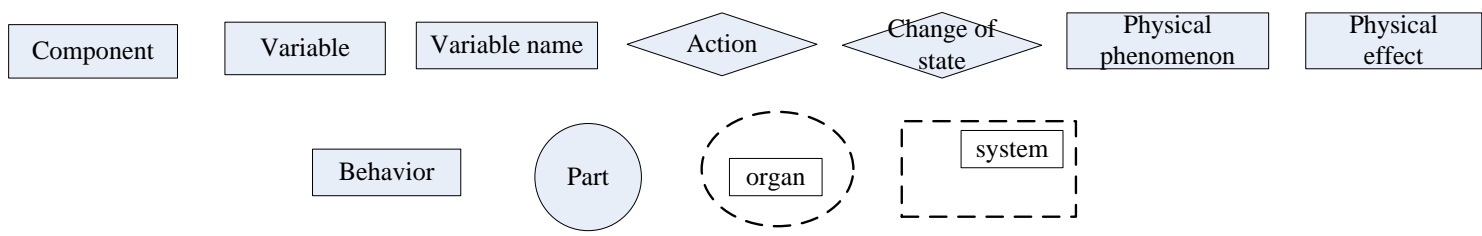

Array of components Array of variable

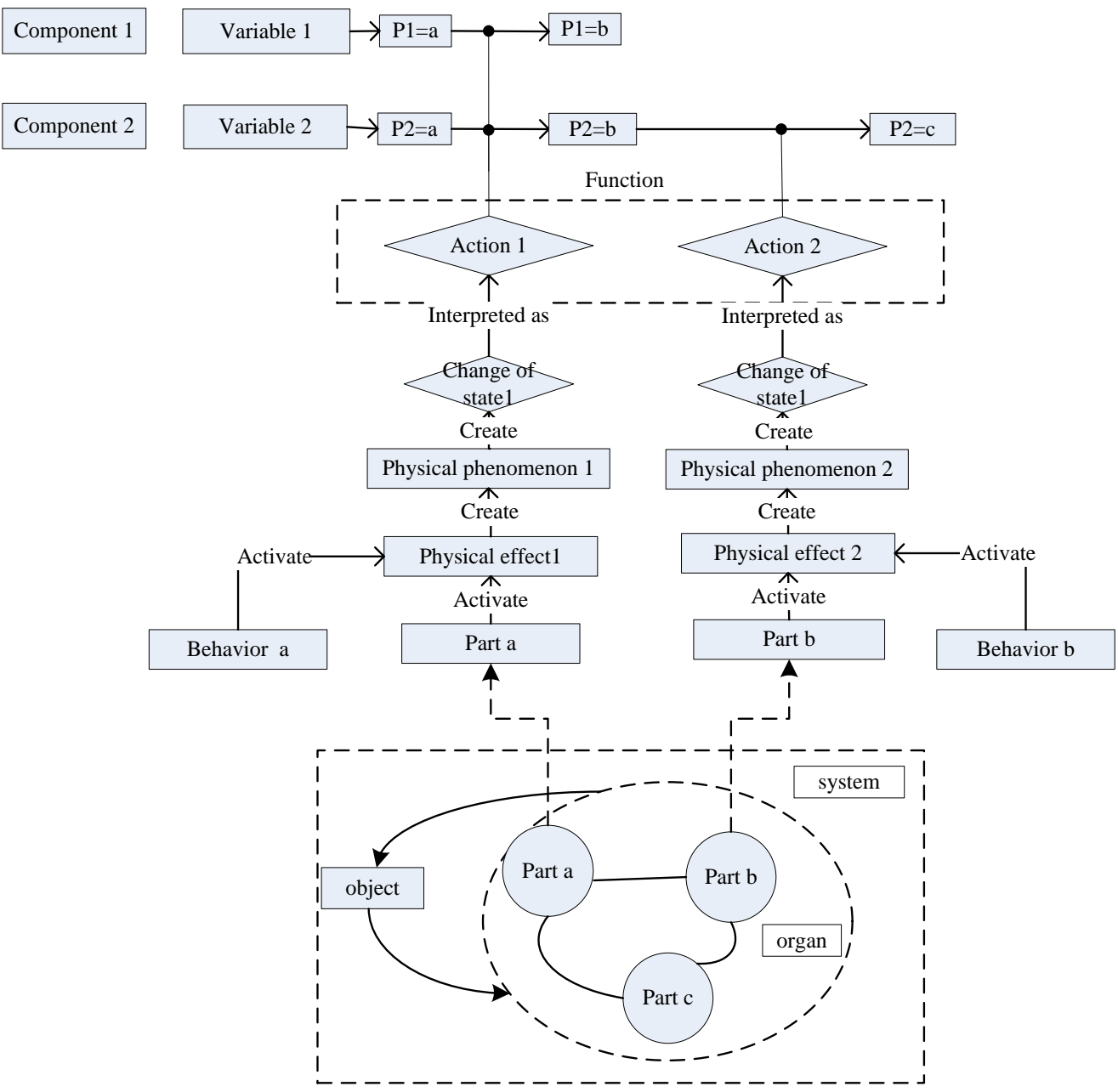

Figure 1: UNO-BID model diagram. Appendix B shows an example. A complete description of elements can be found in Rosa et al. (2015).

Briefly, the elements representing system structure are based on DANE, in which organs are represented as combinations of parts, while the causal relations among the system components are derived from 
SAPPhIRE. Changes of state are described in DANE function definition and directly linked to the corresponding causal representation based on SAPPhIRE. The complete list of the elements with their specific definitions can be found in Rosa et al. (2015).

\subsection{Multi-Biological Effects}

Multi-Biological Effects (MBE) is an extended version of the notion of effect in the Theory of Inventive Problem Solving (TRIZ) (Altshuller, 1999; Cascini, 2012).

It attempts to apply biological knowledge to creatively solve engineering design problems (Wei et al., 2015). MBE is a combination of the Functional Model of the Systematic Design approach (Pahl et al., 2007) and the Substance-Field Analysis (SFA) of TRIZ (Altshuller, 1999).

The elements in MBE include subjects, attributes, behavior, components, functional flows, inputs and outputs, properties of behaviors, tags of change, interactions and environment. Their specific definitions can be found in Wei et al. (2015). Figure 2 illustrates the archetype of the MBE model, while Appendix C shows an example.

Legend of the symbols

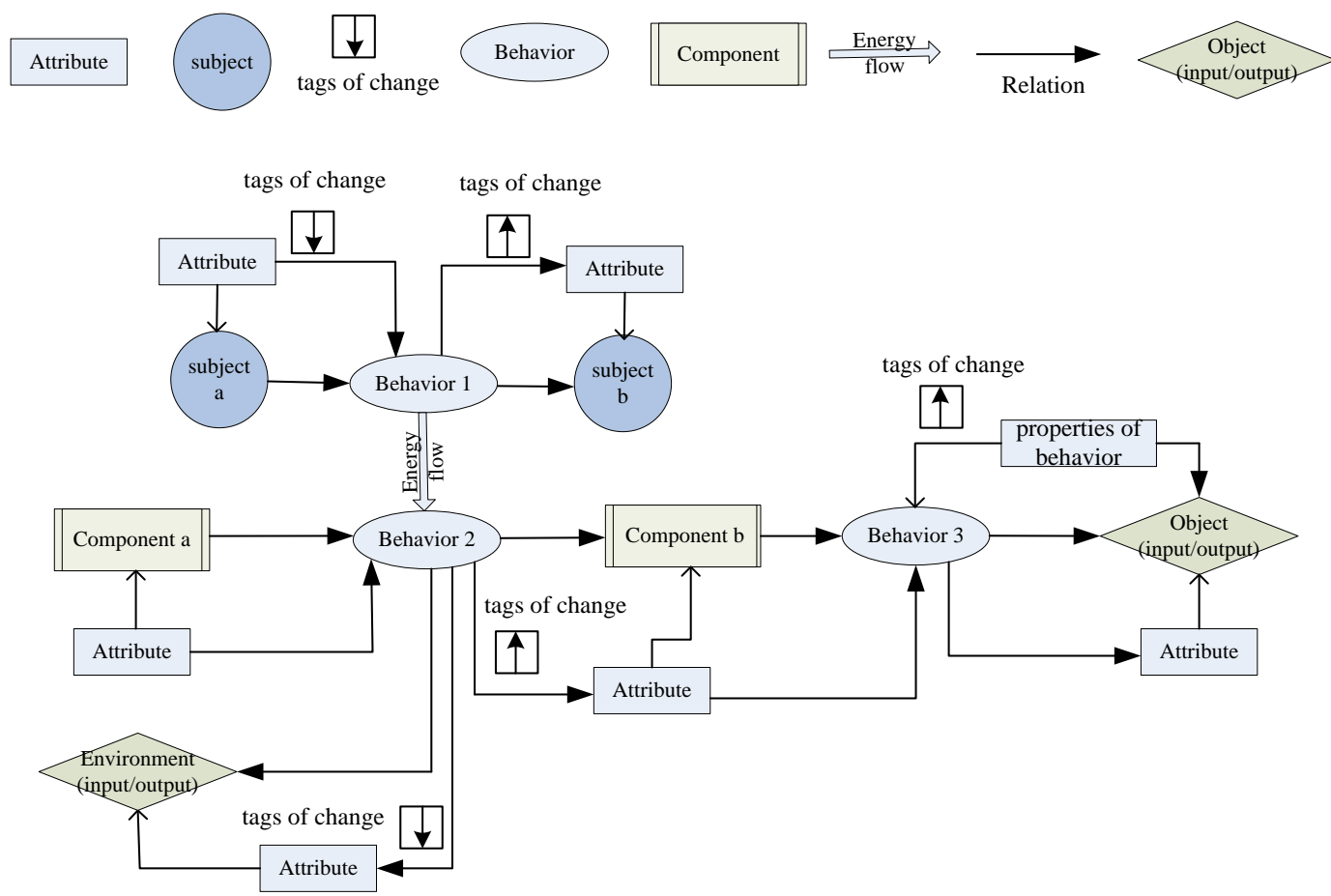

Figure 2: The archetype of the MBE model

\subsection{Experimental tests on FB-BID models}

All these models have been validated by means of experimental tests, i.e., by analyzing the outcomes of experienced and/or novice designers when supported by one or more of these models. The analyses of these experimental results have been conducted with several approaches, depending on the aims of the tests, and all of them demonstrate that the proposed model can improve one or more aspects of the design process.

For example, Srinivasan et al. (2010) and Keshwani et al. (2017) investigated the effect of adopting SAPPhIRE on the novelty of design process outcomes, while Siddharth et al. (2018) experimentally examined novelty and requirement-satisfaction (two major indicators of creativity) of the resulting design solutions. Helms et al. (2010) used an experimental approach to determine "what external representations, such as text, diagrams, or structured knowledge representations, best help biologists and engineers develop 
an adequate understanding of biological systems to support biologically inspired engineering design." It is also worth to notice that the DANE research group also used tests with students to define the DANE model itself and then continued to use experimental tests to advance the development (Goel et al., 2010; HmeloSilver et al., 2010).

On the other hand, very few scholars have compared different models. One of the more recent and broad experimental analyses of this type was described and discussed by Fayemi et al. (2017). They identified 22 tools and studied their use and effects in a complete design process, with the aim of helping designers select the most appropriate tool for each phase of the design process.

The original contribution of this paper is to extend the experimental approach to the comparison of several FB modeling techniques: first, it proposes a benchmark of 4 FB modeling techniques against the most common open-access online BID database, namely AskNature; second, it goes beyond other reviews available in the literature, such as the above-mentioned Fayemi et al. (2017), by introducing quantitative metrics for the comparison of the analyzed BID techniques.

Table 1: The Outline of the Experiment

\begin{tabular}{|c|c|c|c|c|c|c|c|c|}
\hline Task & Time & Group & 1 & 2 & 3 & 4 & 5 & 6 \\
\hline- & START & ALL & \multicolumn{6}{|c|}{ Instruction of experiment } \\
\hline \multirow{2}{*}{1} & \multirow{2}{*}{$30 \mathrm{~min}}$. & Task & \multicolumn{6}{|c|}{ Design an individual alarm } \\
\hline & & Model & \multicolumn{6}{|c|}{ None } \\
\hline \multirow{3}{*}{2} & $2 \mathrm{~min}$. & ALL & \multicolumn{6}{|c|}{ Provide and pass out the BID material } \\
\hline & \multirow{2}{*}{$28 \mathrm{~min}}$. & Model & None & AskNature & DANE & SAPPhIRE & UNO-BID & MBE \\
\hline & & Task & \multicolumn{6}{|c|}{ Design a device capable of adhering to a smooth surface } \\
\hline \multirow{3}{*}{3} & $2 \mathrm{~min}$. & ALL & & & ide and $\mathrm{p}$ & out the BID & terial & \\
\hline & \multirow{2}{*}{$28 \mathrm{~min}}$. & Model & None & AskNature & DANE & SAPPhIRE & UNO-BID & MBE \\
\hline & & Task & \multicolumn{6}{|c|}{ Design a device to grab objects for wheelchair users } \\
\hline- & END & ALL & \multicolumn{6}{|c|}{ Collect the results } \\
\hline
\end{tabular}

\section{Organization of the experiment}

According to the goal of this study, a three-round design experiment was conceived to compare the performance of FB models in supporting students when they are asked to conceive new technical solutions based on biological knowledge. Table 1 summarizes the overall structure of the experiment.

The 30 participants were randomly divided into 6 groups with 5 persons in each. Twenty-five students were male, while the other five students were female; six were 22 years old, 20 students were 23 years old and the other four students were 24 years old. Group 1 was the control group; no BID model was therefore provided to this group during the whole experiment. The other five groups were provided with models representing some biological systems relevant to addressing the design problem. Each subject worked autonomously.

The first design task was aimed at confirming that the subjects had equivalent aptitude and skills in addressing design ideation tasks.

Rounds 2 and 3 were designed to compare the five approaches selected. The difference between Task 2 and Task 3 is the complexity of the proposed challenge: students were requested to fulfill only one functional requirement in Round 2, while Round 3's design task consisted of 2 functional requirements. The 2 functional requirement design task was included as a first attempt to evaluate the impact of the degree of complexity of the design task. The experimental tests of BID models available in the literature mentioned in the previous section were carried out with subjects addressing simple design tasks featuring a single functional requirement. This paper goes beyond the common practice by comparing the outcome of BID models with different degrees of design task complexity. 


\subsection{Description of the Experiment's Rounds}

In the first round, the subjects were asked to design a personal alarm, a problem derived from a previous experimental study (Durand et al., 2015). In the second round, the subjects were asked to develop concepts for a device capable of adhering to smooth surfaces such as glass. The third design required the development of a device allowing wheelchair users to pick up objects from high shelves. Appendix D contains the text of these design problems.

In all three rounds, the subjects were provided with a brief description of the functional requirements and the main customers' needs in the design problem, with a representation of some relevant biological systems.

Students were asked to represent their solutions with sketches and to add a brief explanation of the solution. Appendix E and Appendix F show a couple of the solutions conceived by the students. In order to encourage the students to work hard, the participants were informed that the university would fully fund the patent application of any original and valuable ideas produced in the test.

\subsection{BID Stimuli}

As shown in Table 1, each subject (except those in Group 1) was provided with the representation of several biological strategies created using the approach associated with the student's group. Specifically, participants belonging to group 2 used AskNature pages, while group 3, 4, 5 and 6 students were supplied with DANE, SAPPhIRE, UNO-BID, and MBE models, respectively.

These models were printed in color and distributed to participants according to the timing in Table 1 .

\subsection{Timeline}

First, the instructors in charge of handling the experiment explained the organization, rules ${ }^{2}$ and expected outcomes of the experiment. The participants then had 30 minutes to complete each design round. During the test, students could freely ask for clarifications about the provided material. All the design ideas generated by the participants were collected at the end of each round of the experiment.

\section{Test Evaluation Metrics}

The design creativity metric proposed by Shah et al. (2000) was adopted to assess the results of the design experiment. This method is widely used in estimating the effectiveness of design methods (Cascini et al., 2018; Nelson et al., 2009; Wilson et al., 2010; Kim et al., 2014; Vandevenne et al., 2016). This approach relies on four dimensions to assess the ideas generated: quantity, quality, novelty and variety.

\subsection{Quantity}

Quantity evaluation was based directly on the number of ideas generated during a design round (Vandevenne et al., 2016; Shah et al., 2000). It is an important indicator of the workability of idea generation methods (Shah et al., 2003). To determine the value of the quantity indicator, the evaluators need to identify the unique ideas and discard the duplicated ones. The identification of duplicate solutions (i.e., based on the same idea) and of non-acceptable solutions (i.e., that do not meet the design requirement and/or were not completed) was done on the basis of the criteria presented by Linsey et al. (2005) and by Vandevenne et al. (2016).

\footnotetext{
${ }^{2}$ The subjects had to perform the ideation activity by themselves: mutual communication, smartphones, tablets and computers were not permitted in order to avoid any external information sources aside from the intended biological stimuli.
} 


\subsection{Quality}

Quality is related to the feasibility of a proposed solution as well as to its relevance to the design requirements. The evaluators adopted the criteria presented by Dean et al. (2006), by Verhaegen and Duflou (2013) and by Linsey (2007).

Table 2: Evaluation Scale for Quality

\begin{tabular}{|c|c|}
\hline Score & Guidance \\
\hline 9 & $\begin{array}{l}\text { Perfect: Solution has high relevance and workability and clarifies the } \\
\text { descriptions found in both pictures and text. }\end{array}$ \\
\hline 7 & $\begin{array}{l}\text { Good: Solution has high relevance and good workability illustrated by the } \\
\text { picture and text description. }\end{array}$ \\
\hline 5 & $\begin{array}{l}\text { Medium: Solution is moderately relevant to the design task and has adequate } \\
\text { feasibility with a simple description. }\end{array}$ \\
\hline 3 & $\begin{array}{l}\text { Relatively poor: Solution is relevant to design requirements but has limited } \\
\text { practicality in terms of its pictures and text descriptions. }\end{array}$ \\
\hline 1 & $\begin{array}{l}\text { Very poor: Relevant concept has a very poor description, or the ideas are } \\
\text { obviously irrelevant. }\end{array}$ \\
\hline
\end{tabular}

In brief, the quality of design concepts was evaluated using a five-level scale. If the idea was judged technically unfeasible, its quality scored zero; on the opposite end, an idea that appeared to be very easily feasible was given a score of nine. Table 2 describes this scale in detail. Deeper and more detailed analyses were not judged appropriate since the subjects of this experiment were undergraduate students with very limited practical experience.

If the design problem had more than one functional requirement, its global quality score was evaluated as a weighted average of the quality score of each functional requirement, according to Equation 1:

$$
\begin{aligned}
& V_{q}=\sum_{i=1}^{n} \omega_{i} \cdot m_{i} ; \\
& \sum_{i=1}^{n} \omega_{i}=1
\end{aligned}
$$

where $V_{q}$ is the global quality score; $m_{i}$ is the quality score for each functional requirement, and $\omega_{i}$ is the weight of the $i^{\text {th }}$ functional requirement defined based on the importance of the functional requirement itself. The sum of all the weights $\omega_{i}$ must be equal to 1 .

\subsection{Novelty}

Novelty reflects how unusual and unique a design concept is with respect to all the other ideas generated during the design challenge (Glier et al., 2014). This parameter can be also adopted as an indicator to estimate the strength of what is called confirmation bias (CB) (Hallihan \& Shu, 2013). A higher novelty score means a lower CB.

It is worth noting that the decision to evaluate novelty only with respect to the solutions generated by the students mainly rested on their limited experience in the specific field and the fact that they could not perform an internet search for existing solutions. In other words, it was assumed that those who generated more original solutions were triggered by the BID stimuli rather than by previous professional experiences or external sources of information.

By adopting the approach based on the Genealogy Tree (Shah et al., 2003), the novelty score of each concept can be calculated using Equation 2: 


$$
M_{1}=\sum_{j=1}^{m} f_{j} \sum_{k=1}^{n} S_{1 j k} \cdot p_{k}
$$

where $M_{l}$ is the overall novelty score of the concept involving $m$ functional requirements, $n$ is the total number of abstract levels in the Genealogy Tree, $f_{i}$ and $P_{k}$ are the weights of the functional requirements and abstract levels, respectively, and $S_{l j k}$ is the novelty score for ideas on the different abstract level obtained by using Equation 3:

$$
S_{1 j k}=10 \times \frac{T_{j k}-C_{j k}}{T_{j k}}
$$

where $T_{j k}$ expresses the overall number of ideas that meet the $j^{\text {th }}$ functional requirement on the $k^{\text {th }}$ level of abstraction, while $C_{j k}$ is the number of solutions originating from common knowledge in the field, according to the procedure described by Shah et al. (2003).

\subsection{Variety}

Variety measures the diversity among groups of solutions based on their distances on the Genealogy Tree (Shah et al., 2003).

The variety score for the concepts generated by a participant was determined using Equation 4 (Nelson et al., 2009), which is an improvement on the original method described by Shah et al. (2003):

$$
V=\sum_{j=1}^{m} f_{j}\left(S_{1}\left(b_{1}-1\right)+\sum_{k=2}^{4} S_{k} \sum_{l=1}^{b_{k-1}} d_{l}\right)
$$

where $V$ expresses the final variety value, $f_{i}$ is the weight value of the $j^{\text {th }}$ functional requirement, $m$ is the total number of functions, $S_{k}$ is the weight at the $k^{\text {th }}$ level; $b_{i}$ is the number of branches on the $i^{\text {th }}$ level and $d_{l}$ is the number of differentiations at node $l^{\text {th }}$. A detailed description is available in Nelson et al. (2009) and Shah et al. (2003).

\section{Results of the experiment}

Before presenting and discussing the results of the experiment, it is worth noting that two different evaluators were recruited to assess the quantity and quality metrics in order to limit the effects of prejudice in idea assessment (Montag-Smit et al., 2017). The Pearson Correlation Coefficient analysis was used to evaluate whether there was a significant discrepancy between the evaluators' assessments. This analysis demonstrated that evaluators' marks were in close agreement: the Pearson Correlation Coefficient ranged from 0.829 (quality) to 1.0 (quantity) (Robson et al., 2002). Therefore, it seems acceptable to use the average of the two evaluators' evaluations for the statistical analyses.

\subsection{Analysis of the first design task}

This subsection presents the participants' performance during the first design round. Figure 3 shows the mean scores of the four dimensions with the 95\% confidence interval (95\% CL).

First, a test of homogeneity of variance (Levene's test) was performed. The result of this statistical test was 0.301 , which, being larger than the threshold (0.05), indicates that the differences obtained in sample variances are compatible with random sampling from a population with equal variances.

The ANOVA test was then used to analyze the outcomes of this first design round. The results of this test (Figure 3 and Tables 3 and 4) show that there is not a significant difference between the groups, since 
the confidence bands of all groups overlap for all the four dimensions, and the statistical significance is always higher than the threshold value. Novelty, however, reveals a certain difference between groups 1 and groups 5 and 6. Based on Levene's test, we assumed that this apparent discrepancy does not affect the results obtained during the other two rounds of the test and their analyses (Seltman, 2012; Schmidt, 1996).

Furthermore, according to the ANOVA test, the strength of correlation $(r)$ among the results of three design rounds ranged from -0.293 to 0.447 , which indicates that there is no evident correlation among their outcomes. In other words, better performance in the baseline test does not necessarily imply good performance in the second and/or in the third design rounds. Therefore, it can be concluded that the outcomes of each round should and could be analyzed independently.

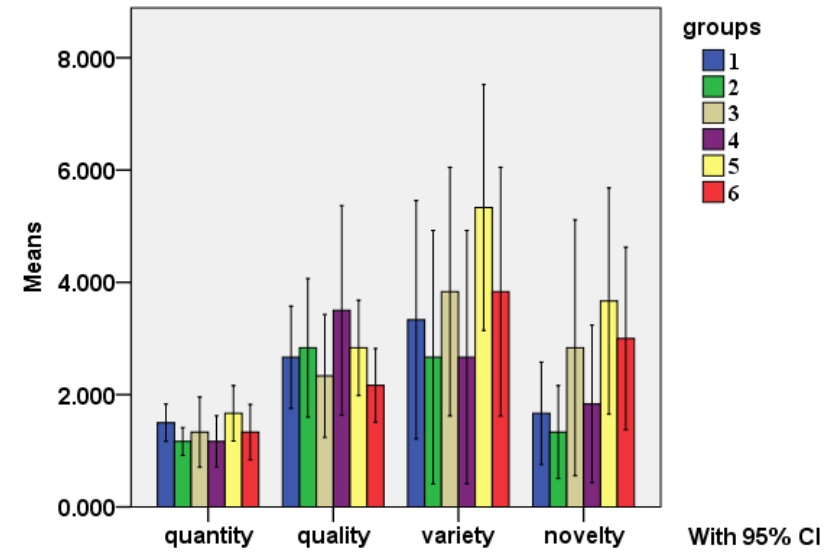

Figure 3: Mean scores in the baseline task. 1: Control group, 2: AskNature, 3: DANE, 4: SAPPhIRE, 5: UNO-BID, 6: MBE

\subsection{Influence of BID stimulus}

This section aims to investigate the influence of BID stimuli on students' ideation performance.

\subsubsection{General comparison}

In this subsection, we first evaluate the differences between the control group and all the other groups together, in order to evaluate if and how a generic BID stimulus can enhance the ideation performance of the subjects.

Figure 4 illustrates this comparison with the 95\% CLs. In the second round, there was a quite evident improvement in variety and novelty. The results of the ANOVA test, however, indicate that only the novelty score improvement is statistically significant. On the other hand, higher average values for quality and novelty can be observed in the third design round, but the ANOVA test indicates that only the novelty improvement has statistical significance $(\mathrm{p}<0.05)$.

As found in previous studies (Vandevenne et al., 2016; Chakrabarti, 2009), it can therefore be inferred that introducing biological knowledge to the engineering design process can increase the novelty of the designs.

Before discussing these results in more detail, it is worth remembering that the outcomes of each round should and could be analyzed independently.

\subsubsection{Group by group comparison}

In this section, we analyze the experimental results in more detail by comparing the results of each group (from 2 to 6, i.e., the groups with a specific BID stimulus) to the control group (1). 


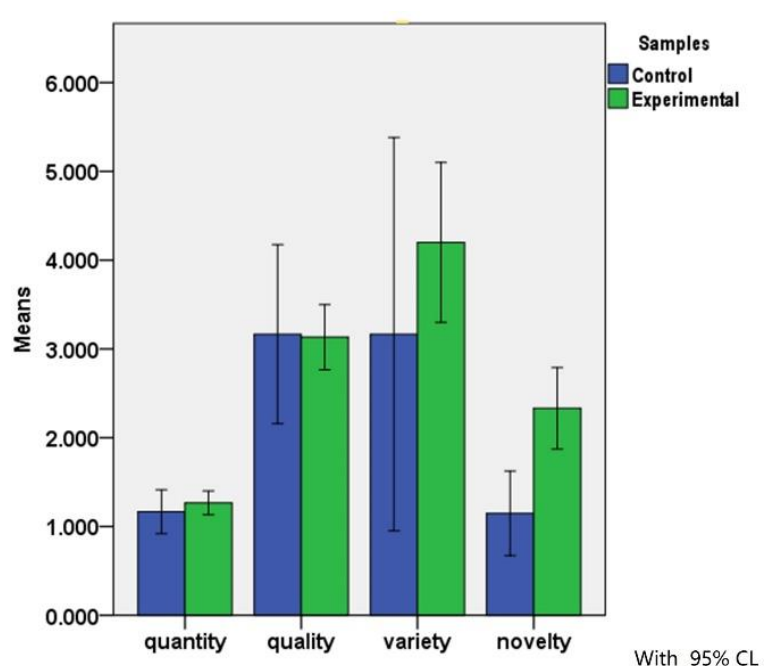

(a) Mean score of metrics for condition of stimulus in task 2

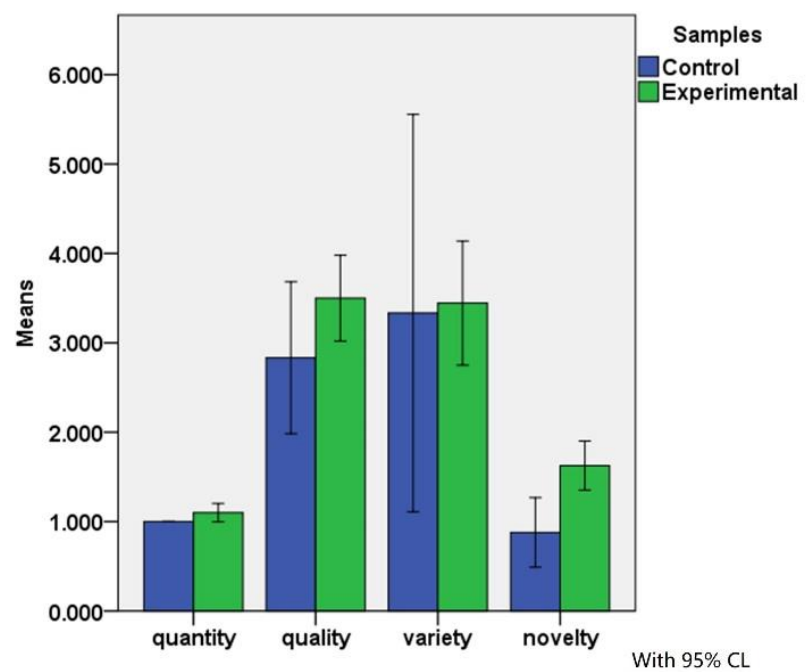

(b) Mean score of metrics for condition of stimulus in task 3

Figure 4: Comparison of the performance of the experimental group against the control

Figure 5 summarizes the outcomes of this comparison for the second (single function design problem) and third design rounds (two-function design problem).

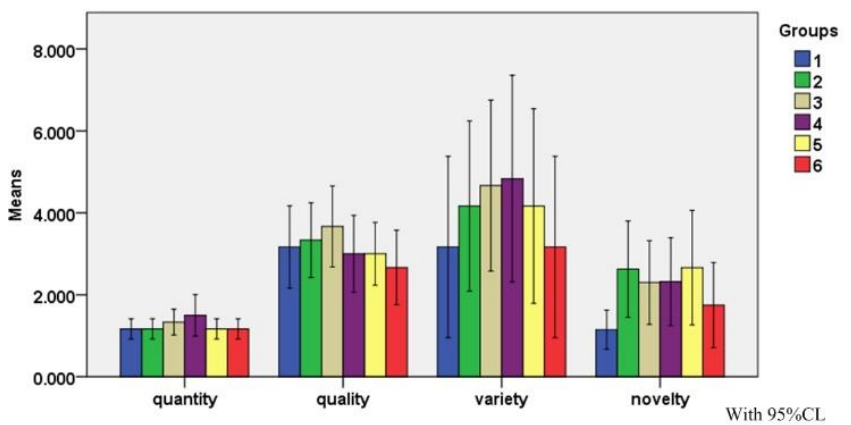

(a) Relevant comparison for individual group of task 2

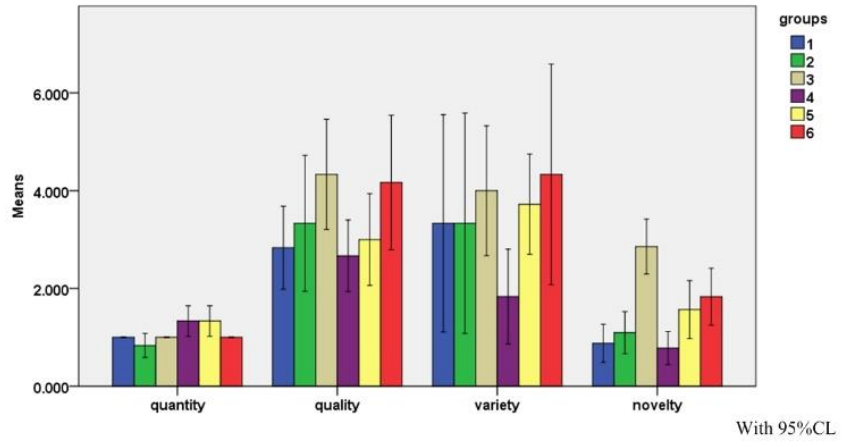

(b) Relevant comparison for individual group of task 3

Figure 5: Comparison of performance from the individual group 1: Control group, 2: AskNature, 3: DANE, 4: SAPPhIRE, 5: UNO-BID, 6: MBE

Table 3 summarizes the results of the ANOVA test results by comparing the control group with all the other participants, while Table 4 summarizes these results: the up arrow identifies the situations where the specific FB model improved designer performance in some way.

Considering only the differences that were statistically significant according to ANOVA, the more evident result of the analysis of the second round is the higher novelty score that can be observed in all groups. Specifically, while the novelty increments in group 2 (users of AskNature) and group 5 (users of 
UNO-BID) satisfy the statistical significance requirement, DANE and SAPPhIRE users barely satisfy this requirement. MBE influence on novelty in this second round does not seem to be very evident.

Table 3: Mean scores and ANOVA test results for all the metrics of individual groups 1: Control group, 2: AskNature, 3: DANE, 4: SAPPhIRE, 5: UNO-BID and 6: MBE Single underlined $p$-values are less than or equal to 0.105 ; double underlined $p$-values are less than 0.05 .

\begin{tabular}{|c|c|c|c|c|c|c|c|c|c|}
\hline \multirow{2}{*}{ Tasks } & \multirow{2}{*}{ Group } & \multicolumn{2}{|c|}{ Quantity } & \multicolumn{2}{|c|}{ Quality } & \multicolumn{2}{|c|}{ Variety } & \multicolumn{2}{|c|}{ Novelty } \\
\hline & & Mean & $p$-value & Mean & $p$-value & Mean & $\mathrm{p}$-value & Mean & p-value \\
\hline \multirow{6}{*}{2} & $\begin{array}{c}1 \\
\text { (Control) }\end{array}$ & 1.167 & - & 3.167 & - & 3.167 & - & 1.148 & - \\
\hline & $\begin{array}{c}2 \\
\text { (AskNature) }\end{array}$ & 1.167 & 1.000 & 3.333 & 0.780 & 4.167 & 0.492 & 2.626 & $\underline{\underline{0.035}}$ \\
\hline & $\begin{array}{c}3 \\
\text { (DANE) } \\
\end{array}$ & 1.333 & 0.415 & 3.667 & 0.403 & 4.667 & 0.304 & 2.300 & $\underline{0.098}$ \\
\hline & $\begin{array}{c}4 \\
\text { (SAPPhIRE) }\end{array}$ & 1.500 & $\underline{0.105}$ & 3.000 & 0.780 & 4.833 & 0.254 & 2.322 & $\underline{0.092}$ \\
\hline & $\begin{array}{c}5 \\
\text { (UNO-BID) } \\
\end{array}$ & 1.167 & 1.000 & 3.000 & 0.780 & 4.167 & 0.492 & 2.662 & $\underline{\underline{0.03}}$ \\
\hline & $\begin{array}{c}6 \\
(\mathrm{MBE}) \\
\end{array}$ & 1.167 & 1.000 & 2.667 & 0.403 & 3.167 & 1.000 & 1.748 & 0.385 \\
\hline \multirow{6}{*}{3} & $\begin{array}{c}1 \\
\text { (Control) } \\
\end{array}$ & 1.000 & - & 2.833 & - & 3.333 & - & 0.879 & - \\
\hline & $\begin{array}{c}2 \\
\text { (AskNature) }\end{array}$ & 0.833 & 0.214 & 3.333 & 0.481 & 3.333 & 1.000 & 1.097 & 0.495 \\
\hline & $\begin{array}{c}3 \\
\text { (DANE) } \\
\end{array}$ & 1.000 & 1.000 & 4.333 & $\underline{\underline{0.037}}$ & 4.000 & 0.561 & 2.857 & $\underline{\underline{\underline{0.000}}}$ \\
\hline & $\begin{array}{c}4 \\
\text { (SAPPhIRE) }\end{array}$ & 1.333 & $\underline{\underline{0.015}}$ & 2.667 & 0.814 & 1.833 & 0.193 & 0.780 & 0.756 \\
\hline & $\begin{array}{c}5 \\
\text { (UNO-BID) } \\
\end{array}$ & 1.333 & $\underline{\underline{0.015}}$ & 3.000 & 0.814 & 3.733 & 0.734 & 1.567 & $\underline{\underline{0.034}}$ \\
\hline & $\begin{array}{c}6 \\
(\mathrm{MBE})\end{array}$ & 1.000 & 1.000 & 4.167 & $\underline{0.063}$ & 4.333 & 0.383 & 1.832 & $\underline{\underline{0.004}}$ \\
\hline
\end{tabular}

Coming to the third round, and still focusing on the differences that are statistically significant according to ANOVA, it can be observed that:

- UNO-BID and SAPPhIRE positively influenced quantity.

- The quality of DANE users' ideas obtained a better ranking.

- The novelty of the concepts generated by DANE, UNO-BID and MBE users was significantly improved.

\subsection{Comments from Test Participants}

In order to collect more direct feedback from the users, a questionnaire (in Appendix A) was given to all participants.

The questionnaire contained four questions:

(1) Test participants were first asked to evaluate the ease of using the model on a scale from -2 (very easy) to 2 (very difficult) and to explain this evaluation. Question 1 answers define the Difficulty of Handling $(\mathrm{DOH})$ index.

(2) Secondly, they were asked to rate the usefulness of the model for the design task and to rate it on a scale ranging from -2 (useless) to 2 (very useful), and to explain this evaluation. The results of the second question were used to determine the Score of Usefulness (SOU).

(3) The third question asked the subjects to point out the most useful or useless parts in the BID model that were assigned to them for the ideation tasks. 
(4) Finally, question 4 was included to collect suggestions on how to improve the BID models assigned.

The answers to this questionnaire were analyzed from two different perspectives. First, a statistical analysis was performed to investigate whether there was an evident correlation between DOH and/or SOU and any dimension of the evaluation metric. Second, the answers to the open questions were qualitatively evaluated.

The statistical analysis did not reveal any evident correlation between DOH and/or SOU and any dimension of the evaluation metric. In other words, the measured quantity, quality, variety and novelty seem to be statistically unrelated to the users' opinions on the FB model usability and/or utility. On the other hand, the users' comments make it clear that one of the major difficulties for users is understanding how the biological system works.

Among the subjects in groups 3, 4, 5 and 6, many asked for a picture of the biological system and/or for a "qualitative" description of it, while a couple of subjects working with the AskNature model asked for a more detailed description of the features of the biological entity, while appreciating the usefulness of the "descriptive modeling." Furthermore, several subjects provided with the DANE, UNO-BID and MBE models complained that these models contained too many details and/or relationships among elements, making the representation difficult to understand.

\section{Discussion}

The statistical analyses of the experiment have shown that the influence of FB models on design outcomes is quite complex. The same piece of biological knowledge seems to have a different effect on students' ideation process depending on how it is coded and transferred to the students.

\subsection{FB models and novelty}

According to previous studies (see, for example, Vandevenne et al., 2016, for AskNature), the results of these tests have demonstrated that a BID stimulus mostly influences the novelty of the conceived solutions, but the results of this study shed more light on this finding.

This influence, in fact, seems also to depend on the number of functional requirements in the design problem. Specifically, it can be observed that for the students who participated in the test:

- AskNature and SAPPhIRE seem to be more effective for novelty in single-function design problems (the type of problem subjects faced in Vandevenne et al., 2016).

- MBE significantly enhanced novelty only for the two-function problem; this can be ascribed to the greater complexity of the way information is represented in this model, which makes it less effective on simpler tasks but provides advantages when dealing with more complex ones.

- UNO-BID and DANE increased novelty in both situations in a statistically significant manner.

An aspect that deserves some reflection is that SAPPhIRE and AskNature users do not achieve this result when they are asked to tackle a two-function design problem. Although the two approaches are profoundly different in nature, the former being rigorously structured to represent causal relationships, the second being purely narrative, they turn out to behave similarly when the complexity of the design task increases. This seems to be related to the difficulty users have in properly handling all the information provided by the two techniques. On the other hand, UNO-BID and DANE provide a representation where some essential information becomes prominent, thus becoming more usable when complexity increases.

\subsection{Influence of FB models on quality and quantity}

Table 3 shows that some correlations have a p-value slightly higher than the usual statistical significance threshold (0.05), while all the others exhibit a much higher p-value. It was, therefore, decided to ascribe a weak significance to the correlations that have p-values up to 0.105 .

Regarding the other dimensions of the evaluation metric, it can be noted that none of the BID models seems to have had a strictly statistically significant influence on quantity, quality and variety during the 
second (single function) design round. On the contrary, during the third (two-function) design round, DANE and MBE seemed to improve quality, while SAPPhIRE and UNO-BID seemed to increase the quantity of the solutions generated by the students. No effect was noticeable on variety in this round.

Apropos of quantity, it seems that if the problem is simple (i.e., only containing a single functional requirement), the students did not benefit from the structured information, while the FB models that more clearly describe the causal relationships among input and effect (SAPPhIRE and UNO-BID; see Sections 2.3 and 2.4) seemed to positively influence students' results in the two-function design round.

On the other hand, the common and relevant trait of the two models that enhance design quality (DANE and MBE) in the two-function design round is their provision of a clearer description of the system's structure (see Sections 2.2 and 2.5). A deeper understanding of system organization and function, in fact, may have helped students in better organizing the concepts of their solutions, and thus in obtaining better quality.

This observation is partially in contrast with the fact that system structure is also described in UNOBID. A possible explanation for this discrepancy might be that in UNO-BID the correlation between system elements and change of state is not direct (as in DANE and MBE) but passes through a SAPPhIRE diagram.

Table 4: Statistically significant effects of FB Models.

Bold arrows indicate statistically significant correlations in $\mathbf{p}$-values $<0.05$. Non-bold arrows indicate weak correlations (0.05<P-Value $\leq 0.105)$.

\begin{tabular}{|c|c|c|c|c|c|c|}
\hline & \multirow{3}{*}{$\begin{array}{c}\text { Fun. } \\
\text { Req. } \\
\text { No. }\end{array}$} & \multicolumn{5}{|c|}{ FB Model } \\
\hline & & AskNature & DANE & SAPPhIRE & UNO-BID & MBE \\
\hline & & 2 & 3 & 4 & 5 & 6 \\
\hline \multirow{2}{*}{ Novelty } & 1 & $\uparrow$ & $\uparrow$ & $\uparrow$ & $\uparrow$ & - \\
\hline & 2 & - & $\uparrow$ & - & $\uparrow$ & $\uparrow$ \\
\hline \multirow{2}{*}{ Quality } & 1 & - & - & - & - & - \\
\hline & 2 & - & $\uparrow$ & - & - & $\uparrow$ \\
\hline \multirow{2}{*}{ Quantity } & 1 & - & - & - & - & - \\
\hline & 2 & - & - & $\uparrow$ & $\uparrow$ & - \\
\hline \multirow{2}{*}{ Variety } & 1 & - & - & - & - & - \\
\hline & 2 & - & - & - & - & - \\
\hline
\end{tabular}

\section{Conclusions}

This paper describes and discusses a three-round design test aimed at comparing the effects of some BID modeling approaches on undergraduate students when they are asked to conceive new solutions for a design problem.

The analysis of the outcomes of these tests confirmed the findings obtained in previous similar studies (Durand et al., 2015) and also shed some light on how FB-BID models enhance the ideation performance of undergraduate students.

First of all, besides confirming their influence on novelty, the outcomes of the experiment showed that this positive influence is also related to design task complexity, i.e., the number of functional requirements: only the DANE, UNO-BID and MBE models improved the novelty score of students in the third round of the test. A possible explanation for this outcome is that engineering students benefit more from models that clearly represent the sequence of state changes occurring in a biological phenomenon when they are asked to concatenate more functions. This result may be somehow related to the students' limited experience in handling more complex systems. Clearly, the results might be radically different if the subjects were industrial designers, who might have more difficulty in dealing with state-change models, while they might have more appreciation for the narrative representation of the BID information.

With regard to quantity and quality, it seems that students do not benefit from any FB-BID model in the single function design task, while some of the FB-BID models have some positive influence on these two parameters in the two-function design task. 
In particular, the FB-BID models that ease the understanding of the causal relationships between inputs and effects seem to be more effective in increasing the quantity of concepts, while the models capable of making systems structure available seem to have some influence on the quality of concepts. UNO-BID is an exception to this consideration, possibly because the link between structure and function is mediated by a SAPPhIRE representation of the behavior.

Finally, it seems that FB-BID models do not have any influence on variety in either design task.

The above considerations, combined with the feedback provided by the students through the responses to the questionnaire, suggest the following possible improvements to FB-BID models:

- Represent more clearly and explicitly the relationships between the parts of the system and the change of states they undergo.

- Add a qualitative description of the system to the FB-BID models.

Finally, it should be remembered that the entire study was performed by observing the behavior of mechanical engineering students in their $4^{\text {th }}$ year in the bachelor's degree study program. This clearly is a serious limitation since expert practitioners might show significantly different responses in the same situations. Nevertheless, we hope that these findings can provide some useful hints to the scholars who are planning experimental tests in this field.

\section{Acknowledgements}

This paper is sponsored by the National Natural Science Foundation of China (51675159), China Scholarship Council (CSC).

Authors thank Miss Dong Yafan, PhD candidate at Hebei University of Technology, for her invaluable assistance in organizing and carrying out the experiment.

\section{References}

Altshuller, G. (1999), The innovation algorithm: TRIZ, systematic innovation and technical creativity. Technical Innovation Center, Inc.

Baldussu, A., Cascini, G., Rosa, F., \& Rovida, E. (2012), Causal models for bio-inspired design: a comparison, DS 70: Proceedings of DESIGN, 2012.

Cascini, G., Fiorineschi, L., \& Rotini, F. (2018), Impact of Design Representations on Creativity of Design Outcomes, Journal of Integrated Design and Process Science, DOI 10.3233/JID180012.

Cascini, Gaetano (2012), TRIZ-based Anticipatory Design of Future Products and Processes. Journal of Integrated Design \& Process Science, vol. 16, no. 3, pp. 29-63.

Chakrabarti, A. (2009), SAPPhIRE-an approach to analysis and synthesis. In DS 58-2: Proceedings of ICED 09, the 17th International Conference on Engineering Design, Vol. 2, Design Theory and Research Methodology, Palo Alto, California, USA, 8/24-27/2009.

Chakrabarti, A., Sarkar, P., Leelavathamma, B., \& Nataraju, B. S. (2005), A functional representation for aiding biomimetic and artificial inspiration of new ideas. Ai Edam, 19(2), 113-132.

Cohen, Y. H., \& Reich, Y. (2017), Biomimetic Design Method for Innovation and Sustainability. Springer International Publishing.

Dean, D. L., Hender, J. M., Rodgers, T. L., \& Santanen, E. L. (2006), Identifying Quality, Novel, and Creative Ideas: Constructs and Scales for Idea Evaluation, Journal of the Association for Information Systems Vol. 7 No. 10, pp. 646-699.

Deldin, J. M., \& Schuknecht, M. (2014), The AskNature database: enabling solutions in biomimetic design. In Biologically Inspired Design, pp. 17-27, Springer London.

Douglas, L. D., Jillian, M. H., Thomas, L. R., \& Eric, L. S. (2006), Identifying quality, novel, and creative ideas: constructs and scales for idea evaluation. Journal of the Association for Information Systems, 7(10), 646 . 
Durand, F., Helms, M. E., Tsenn, J., McTigue, E., McAdams, D. A., \& Linsey, J. S. (2015), August, Teaching Students to Innovate: Evaluating Methods for Bioinspired Design and Their Impact on Design Self Efficacy. In ASME 2015 International Design Engineering Technical Conferences and Computers and Information in Engineering Conference, pp. V007T06A003-V007T06A003, American Society of Mechanical Engineers.

Fayemi, P. E., Wanieck, K., Zollfrank, C., Maranzana, N., \& Aoussat, A. (2017), Biomimetics: Process, tools and practice. Bioinspiration and Biomimetics, 12(1) doi:10.1088/1748-3190/12/1/011002.

Fu K., Moreno D., Yang M., Wood K. L. (2014), Bio-Inspired Design: An Overview Investigating Open Questions from the Broader Field of Design-by-Analogy. ASME. J. Mech. Des. 136(11):111102111102-18. doi:10.1115/1.4028289.

Glier, M. W., Tsenn, J., Linsey, J. S., \& McAdams, D. A. (2014), Evaluating the Directed Intuitive Approach for Bioinspired Design. Journal of Mechanical Design, 136(7), 071012.

Goel, A. K., Vattam, S., Rugaber, S., Joyner, D. A., Hmelo-Silver, C., Jordan, R., Honwad, S., Gray, S., \& Sinha, S. (2010). Learning Functional and Causal Abstractions of Classroom Aquaria. In Proceedings of the 32nd Annual Meeting of the Cognitive Science Society, Portland, Oregon.

Goel, A. K., Vattam, S., Wiltgen, B., \& Helms, M. (2012), Cognitive, collaborative, conceptual and creative-four characteristics of the next generation of knowledge-based CAD systems: a study in biologically inspired design. Computer-Aided Design, 44(10), 879-900.

Hallihan, G. M. \& Shu, L. H. (2013), Considering Confirmation Bias in Design and Design Research, Journal of Integrated Design and Process Science, Vol. 17, No. 4, pp. 19-35.

Helms, M., Vattam S., \& Goel, A. (2010), The Effect of Functional Modeling on Understanding Complex Biological Systems, in Proceedings of the ASME 2010 International Design Engineering Technical Conferences \& Computers and Information in Engineering Conference - IDETC/CIE 2010, Paper no. DETC2010-28939, August 15-18, 2010, Montreal, Quebec, Canada.

Helms, M., Vattam, S. S., \& Goel, A. K. (2009), Biologically inspired design: process and products, Design Studies, Volume 30, Issue 5, pp. 606-622.

Hmelo-Silver, C., Sinha, S., Gray, S., Jordan, R., Honwad, S., Rugaber, S., Vattam, S., Goel, A. K., Ford, W., \& Schmidt, C. (2010). Appropriating Conceptual Representations: A Case of Transfer in a Middle School Science Teacher. In Proceedings of the Annual Conference of the National Association for Research in Science Teaching, Philadelphia, Pennsylvania, pp. 834-841.

Howard, T. J., Dekoninck, E. A., \& Culley, S. J. (2010), The use of creative stimuli at early stages of industrial product innovation. Research in Engineering Design, 21(4): 263-274.

Kaiser, M. K., Hashemi Farzaneh, H., \& Lindemann, U. (2014), Bioscrabble - the role of different types of search terms when searching for biological inspiration in biological research articles. In DS 77: Proceedings of the DESIGN 2014 13th International Design Conference.

Kennedy, E. B. (2017), Biomimicry: Design by Analogy to Biology, Research-Technology Management, 60:6, 51-56, DOI: 10.1080/08956308.2017.1373052.

Keshwani, S., Lenau, T. A., Ahmed-Kristensen, S., \& Chakrabarti, A. (2017), Comparing novelty of designs from biological inspiration with those from brainstorming, Journal of Engineering Design, 28 (10-12), pp. 654-680, DOI 10.1080/09544828.2017.1393504.

Kim, J. W., McAdams, D. A., \& Linsey, J. (2014), Helping students to find biological inspiration: Impact of valuableness and presentation format. In Frontiers in Education Conference, FIE), 2014 IEEE, pp. 1-6, IEEE.

Linsey, J. S. (2007), Design-by-analogy and representation in innovative engineering concept generation. The University of Texas at Austin. 
Linsey, J. S., Green, M. G., Murphy, J. T., Wood, K. L., \& Markman, A. B. (2005), Collaborating to success: An experimental study of group idea generation techniques. In Proceedings of the ASME Design Theory and Methodology Conference, pp. 24-28.

Madni, A., M. (2007) Transdisciplinarity: Reaching Beyond Disciplines to Find Connections, Journal of Integrated Design and Process Science, March 2007, Vol. 11, No. 1, pp. 1-11.

Montag-Smit, T., \& Maertz, C. P. M. Jr. (2017), Searching outside the box in creative problem solving: The role of creative thinking skills and domain knowledge, Journal of Business Research, Volume 81, December 2017, Pages 1-10.

Nagel, J. K.S., \& Pidaparti, R. M. (2015), Significance, Prevalence and Implications for Bio-Inspired Design Courses in the Undergraduate Engineering Curriculum. In Proceedings of the ASME 2015 International Design Engineering Technical Conferences \& Computers and Information in Engineering Conference IDETC/CIE 2016, Paper No. DETC2016-59661.

Nelson, B., Wilson, J., \& Yen, J. (October 2009), A study of biologically inspired design as a context for enhancing student innovation. In Frontiers in Education Conference, 2009. FIE '09. 39th IEEE, pp. 15, IEEE.

Pahl, G., Beitz, W., Feldhusen, J., \& Grote, K. H. (2007), Engineering design: A systematic approach, 3rd ed., p. 629, London: Springer-Verlag.

Robson, C. (2002), Real World Research: A resource for social scientists and practitioner-researchers, 2nd ed., Oxford: Blackwell.

Rosa, F., Cascini, G., \& Baldussu, A. (2015), UNO-BID: unified ontology for causal-function modeling in biologically inspired design. International Journal of Design Creativity and Innovation, 3(3-4), 177210.

Sarkar, P., Phaneendra, S., \& Chakrabarti, A. (2008), Developing engineering products using inspiration from nature. Journal of Computing and Information Science in Engineering, 8(3), 031001.

Schmidt, F. L. (1996), Statistical Significance Testing and Cumulative Knowledge in Psychology: Implications for training of researchers, 1996): 115.

Seltman, H. J. (2012), Experimental design and analysis. Pittsburgh: Carnegie Mellon University 428.

Shah, J. J., Kulkarni, S. V., \& Vargas-Hernandez, N. (2000), Evaluation of idea generation methods for conceptual design: effectiveness metrics and design of experiments. Journal of mechanical design, 122(4), 377-384.

Shah, J. J., Smith, S. M., \& Vargas-Hernandez, N. (2003), Metrics for measuring ideation effectiveness. Design studies, 24(2), 111-134.

Shu, L. H., \& Cheong, H. (2014), A natural language approach to biomimetic design. In Biologically Inspired Design, pp. 29-61, Springer London.

Siddharth, L., \& Chakrabarti, A. (2018), Evaluating the impact of Idea-Inspire 4.0 on analogical transfer of concepts, Artificial Intelligence for Engineering Design, Analysis and Manufacturing, 32, 431-448, https://doi.org/10.1017/S0890060418000136.

Srinivasan, V., \& Chakrabarti, A. (2007), January, GEMS of SAPPhIRE: A Framework for Designing? In 13th National Conference on Mechanisms and Machines, IISc, Bangalore, India.

Srinivasan, V., \& Chakrabarti, A. (2010), An integrated model of designing. Journal of Computing and Information Science in Engineering, 10(3), 031013.

Srinivasan, V., \& Chakrabarti, A. (2010), Investigating novelty-outcome relationships in engineering design, Artificial Intelligence for Engineering Design, Analysis and Manufacturing, 24, 161-178, doi:10.1017/S089006041000003X.

Srinivasan, V., Chakrabarti, A., \& Lindemann, U. (2013), Towards an ontology of engineering design using SAPPhIRE model. In CIRP Design 2012, pp. 17-26, Springer, London. 
604

605

606

607

608

609

610
Vandevenne, D., Pieters, T., \& Duflou, J. R. (2016), Enhancing novelty with knowledge-based support for Biologically Inspired Design. Design Studies, 46, 152-173.

Vattam, S., Helms, M., \& Goel, A. (2010), Biologically inspired design: a macro cognitive account. In Proc. 2010 ASME Conference on Design Theory and Methods.

Vattam, S., Wiltgen, B., Helms, M., Goel, A. K., \& Yen, J. (2011), DANE: fostering creativity in and through biologically inspired design. In Design Creativity 2010, pp. 115-122, Springer, London.

Verhaegen, P. A., \& Duflou, J. R. (2013), Methods and algorithms for systematic innovation, Doctoral dissertation, PhD Thesis. KU Leuven.

Vincent, J. F., Bogatyreva, O. A., Bogatyrev, N. R., Bowyer, A., \& Pahl, A. K. (2006), Biomimetics: its practice and theory. Journal of the Royal Society Interface, 3(9), 471-482.

Wanieck, K., Fayemi, P., Maranzana, N., Zollfrank, C., \& Jacobs, S. (2016), Biomimetics and its tools. Bioinspired, Biomimetic and Nanobiomaterials, 6(2), 53-66. doi:10.1680/jbibn.16.00010.

Wei Liu, Xiaoting Hou, Guozhong Cao, Runhua Tan (2015), Research on Innovation Driven by Multi Biological Effects and Transcription of Innovative Genes, 5th Advanced Design Concepts and Practice, Sept. 21-23, Hangzhou. 28:1-12.

Wilson, J. O., Rosen, D., Nelson, B. A., \& Yen, J. (2010), The effects of biological examples in idea generation. Design Studies, 31(2), 169-186.

\section{Author Biographies}

Wei Liu, born in 1987, is currently a postdoctoral researcher at the School of Economics and Management and a research associate at the National Technological Innovation Method and Tool Engineering Research Center, Hebei University of Technology in China. He received his doctoral degree in Mechanical Engineering from Hebei University of Technology in China. His primary research interests are innovative design and technological innovation.

Francesco Rosa is an assistant professor at the Department of Mechanical Engineering at the Politecnico di Milano. His main research interests are mechanical design processes and applications in the field of additive manufacturing and geared transmissions. Biologically Inspired Design approaches are among the methods he is exploring.

Gaetano Cascini, holds a Ph.D. in Machine Design and is Full Professor at Politecnico di Milano, Department of Mechanical Engineering. His research interests include Design Methods and Tools with a focus on the concept generation stages for both product and process innovation. He is a member of the Board of Management of the Design Society. He has coordinated several research projects including the European Project Marie Curie-IAPP FORMAT (FORecast and Roadmapping for MAnufacturing Technologies). Currently he is the coordinator of the European projects SPARK: Spatial Augmented Reality as a Key for co-creativity (Horizon 2020 - ICT) and OIPEC: Open Innovation Platform for university-Enterprise Collaboration: new product, business and human capital development (Erasmus+ Capacity Building in Higher Education). He has authored more than 140 papers presented at international conferences and published in authoritative journals and holds 13 patents.

Rhunhua Tan, born in 1958, is currently a professor, a $\mathrm{PhD}$ candidate supervisor, and the president of the National Technological Innovation Method and Tool Engineering Research Center in China. His primary research interests include product design, innovative design and inventive problem solving. 


\section{A. Questionnaire}

625

626

627

628

629

630

631

632

633

634

635

636

637

638

639

640

641

642

643
Q1: Assess the ease of use of the proposed BID models? Explain your choice.

$\square-2$ : Very easy

$\square-1$ : Easy

$\square$ 0: Medium

$\square$ 1: Slightly difficult

$\square$ 2: Very difficult

Q2: Assess the degree of inspiration stimulated by the proposed BID models? Explain your choice.

$\square-2$ : Useless

$\square-1$ : Limited usage

$\square$ 0: Neutral

$\square$ 1: Useful

$\square$ 2: Very useful

Q3: Which part of the BID model was the most useful or useless? Explain your choice.

Q4: Please provide your suggestions to improve the proposed BID model. 

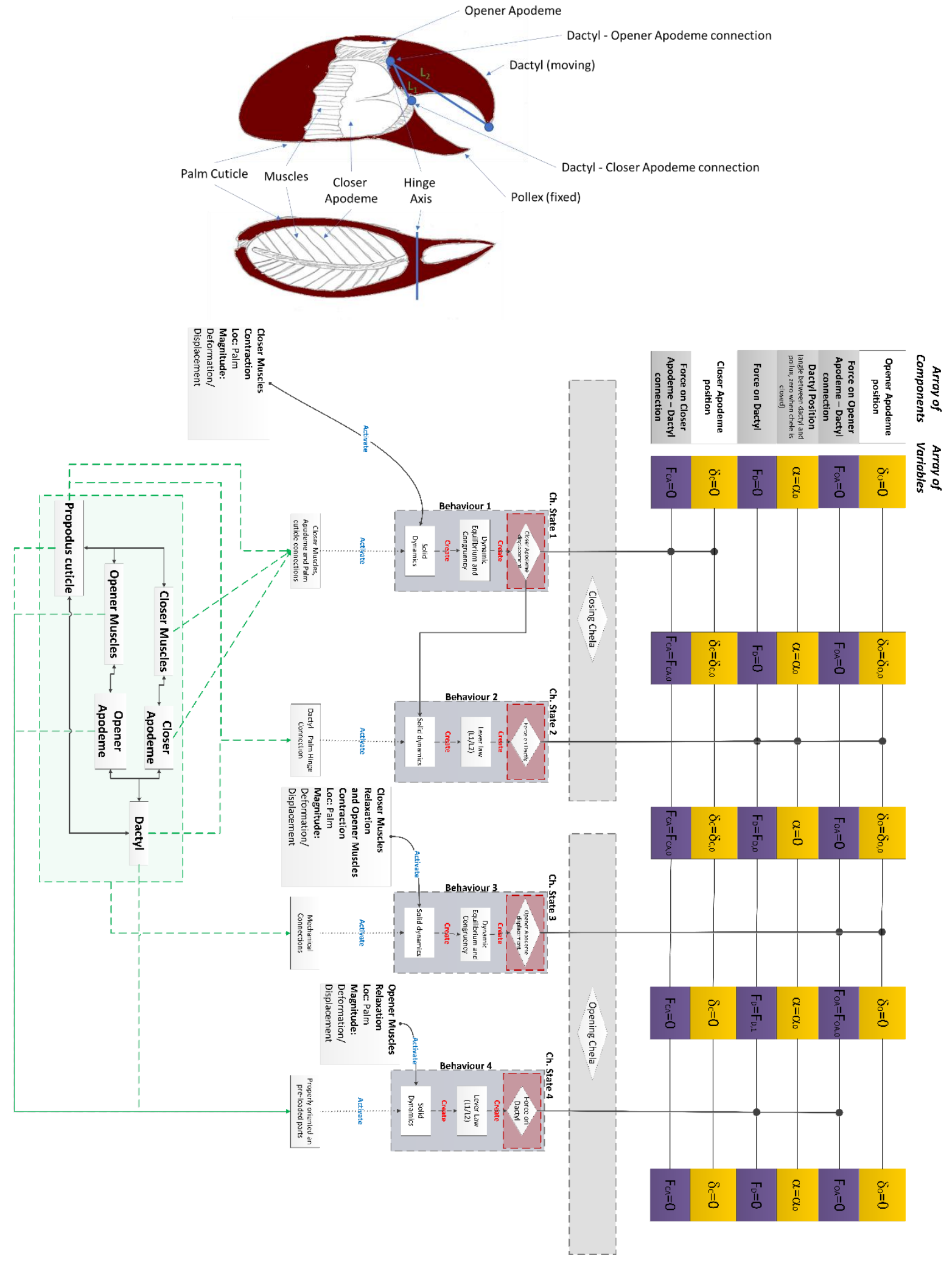


\section{MBE model of a chela of a crab}

\section{Legend of modeling method}

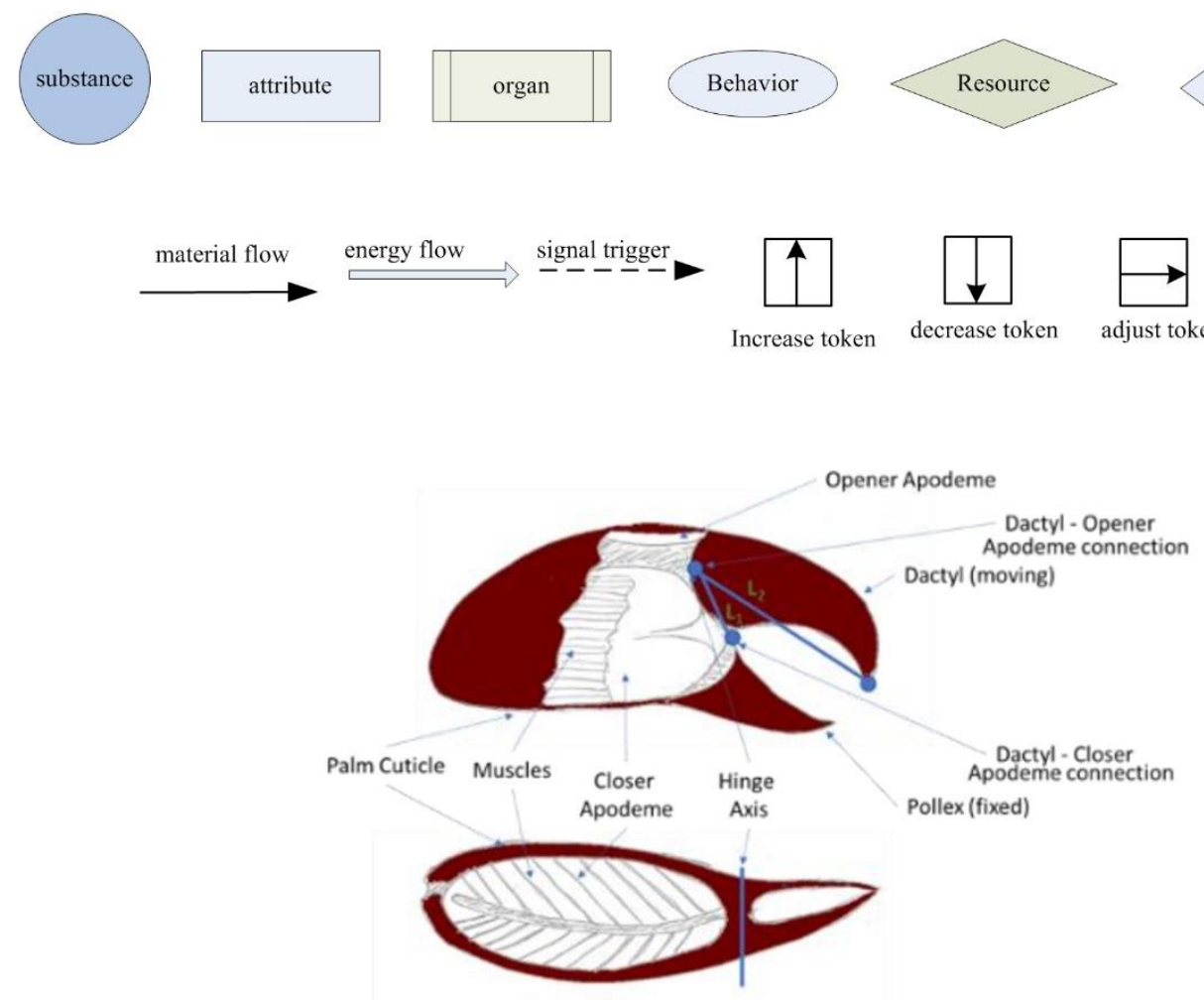

\section{MBE model}

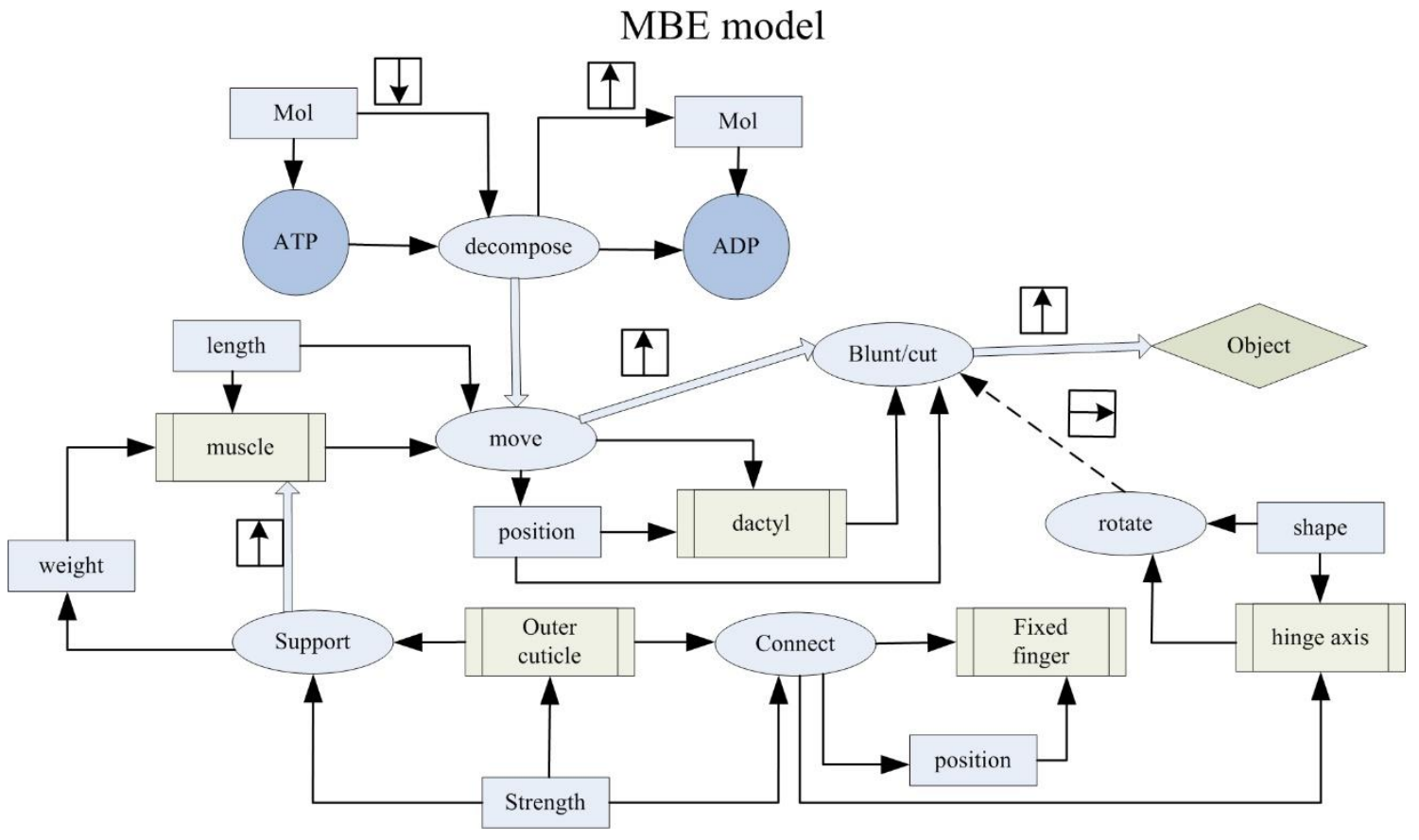




\section{Text of the design problems in Rounds 2 and 3}

650

651

652

\section{Round 2}

Title: A support device can adhere to a smooth surface

Description: A new supporting device is required to adhere to smooth surfaces such as glass or ceramic tiles. This device can sustain a certain load when it is used to support objects.

Main functional requirements: Adhere to the smooth surface with enough strength to support objects.

Specific design parameters: The device:

1) Can adhere to smooth surfaces

659

2) Can sustain a load of up to $500 \mathrm{~g}$ or pull up to $10 \mathrm{~N}$

660

661

662

3) Should be waterproof and work properly in moist conditions

4) Must be low in cost (a prototype should cost less than \$100)

663

664

\section{Round 3}

Title: Grabbing device for the disabled

Description of background: A grabbing device may be very helpful for the disabled, especially if they use wheelchairs. The required device must be able to grab objects of different shapes, textures and consistencies, from solid metal to soft rubber.

Main function requirement: Grab and move objects of different shapes and textures within a certain range of size.

1) The device must grab objects of different shapes within a certain range of size.

2) The device's working distance has to be adjustable. 
676

677

678

679

680

681

682

683

684

685

686

687

688

689

690

691

692

693

694

695

\section{E. Example of students' work - Design Task no. 2}

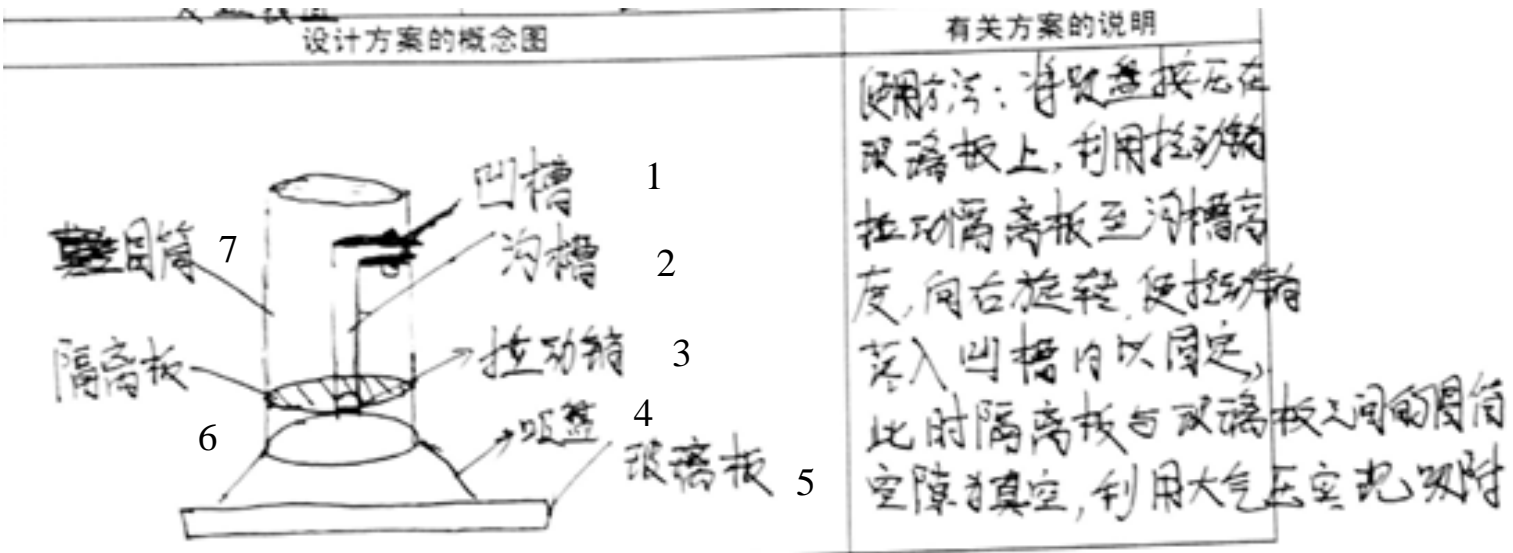

Description: Press the device on the glass, then pull the handle until the piston reaches the groove. Then rotate the handle clockwise and make the handle fall into the fix hole. At this time, the gap between the piston and the glass will generate a certain vacuum that is used to obtain the adhesion.

1. Groove

2. Groove

3. Handle

4. Device

5. Glass

6. Piston

7. Cylinder 


\section{F. Example of students' work - Design Task no. 3}

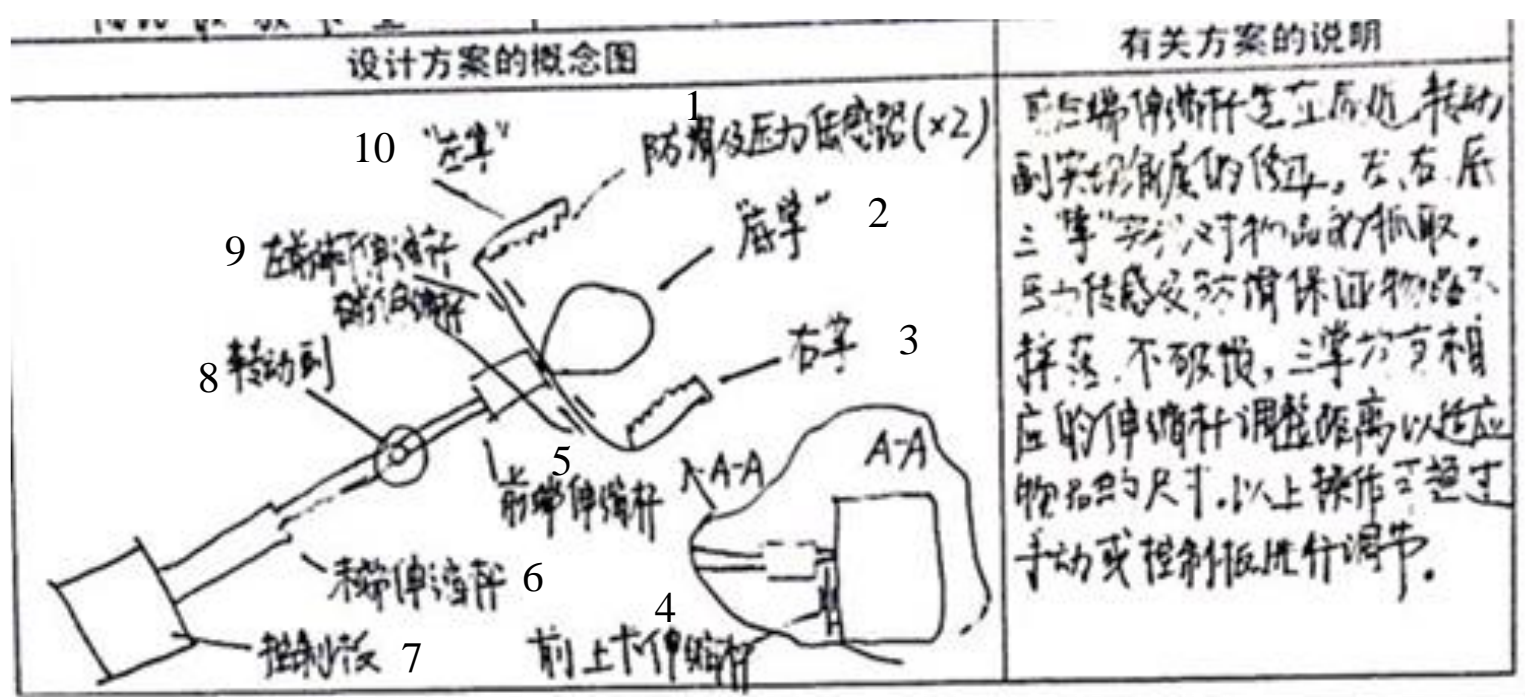

Description: The front and rear telescopic rods are adjustable to accommodate different distances to the objects to be grabbed, the rotational joint is used to adjust the grabbing angles and the three jaws (or pads) (one on the left, one on right and one at the bottom) are used to hold objects. The pressure sensor and the anti-slip structure ensure that the objects will not fall. There are corresponding telescopic rods on the three palms to adjust their working ranges to suit the size of the items. The above operations can be adjusted by manual or automatic control.

1. Pressure sensor and anti-slip structure

2. Bottom jaw

3. Right jaw

4. Telescopic rods of palms

5. Front telescopic rods

6. End telescopic rods

7. Control panel

8. Rotational joint

9. Telescopic rods of jaws

10. Left jaw 